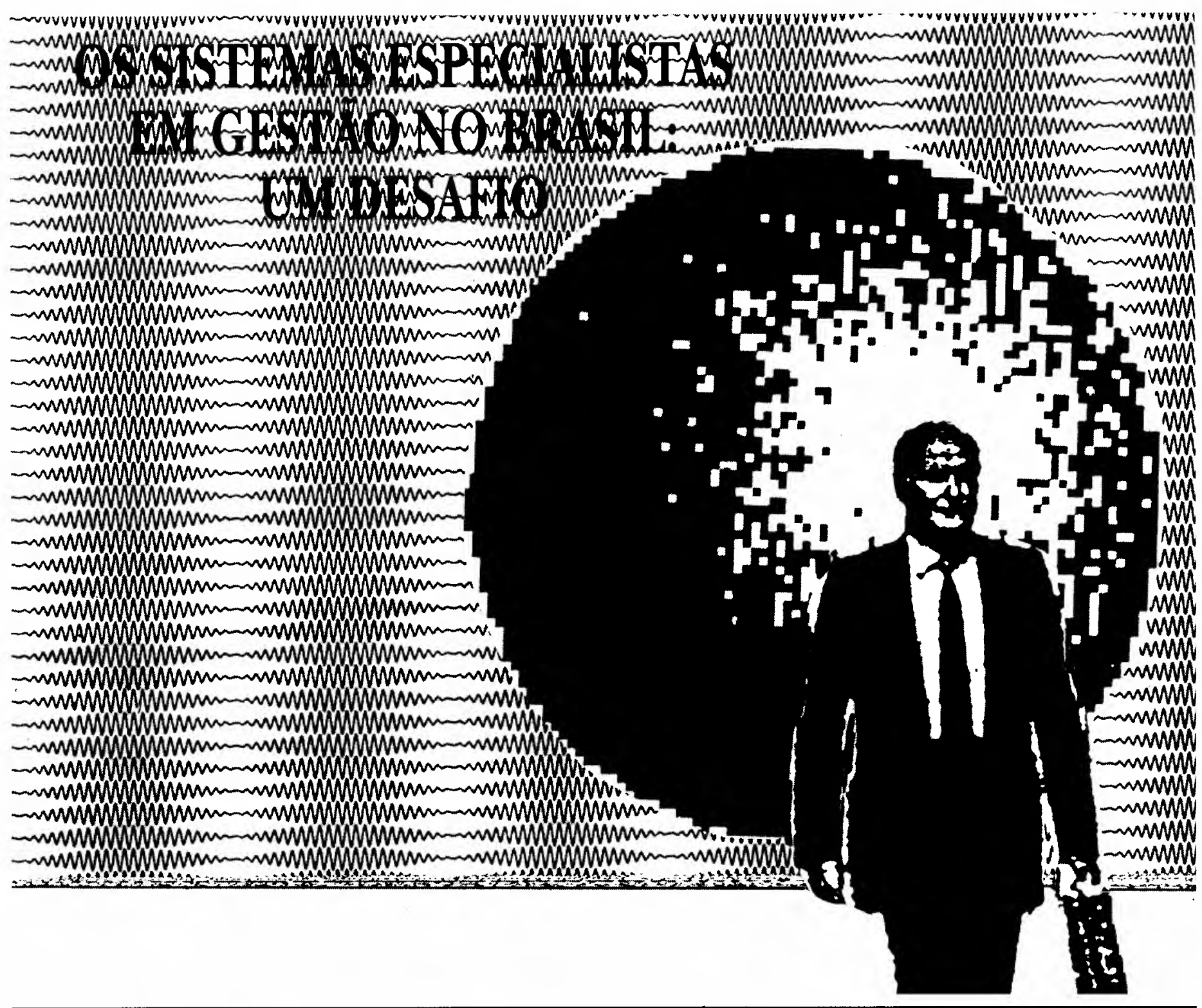

Norberto Hoppen

Doutor em Sistemas de Informação e de Decisão, Universidade de Ciências Sociais de Grenoble, França; Professor na área de Produção e Sistemas, Departamento de Ciências Administrativas e do Programa de Pós-Graduação em Administração da UFRGS.

\section{Jacques Trahand}

Doutor em Administração, Universidade de Ciências Sociais de Grenoble, França; Professor nas áreas de Controle de Gestão e Sistemas de Informação e de Decisão e Diretor da Ecole Supérieure des Affaires de Grenoble, França.

* RESUMO: Este trabalho apresenta uma discussão sobre o potencial que representam os Sistemas Especialistas SE- para a administração de empresas no Brasil. Ele procura destacar o desafio que existe para a efetiva implantação de SE nas organizações no início da próxima década, em termos de benefícios potenciais e limitações. Também procura ressaltar as peculiaridades organizacionais e tecnológicas encontradas no ambiente brasileiro.

* PALAVRAS-CHAVES: Sistema especialista, administração, implementação.

* ABSTRACT: This article discusses the potential benefits of using Expert Systems -ES- to help manage Brazilian organizations. It emphasizes the main issues and challenges of the implementation of ES in the beginning of the next decade. It also stresses the organizational and technological peculiarities of the Brazilian environment.

* KEY WORDS: Expert systems, management, implementation. 


\section{INTRODUÇÃO}

0 $s$ Sistemas Especialistas - SE - representam, atualmente,uma das raras aplicações da inteligência artificial que saiu dos laboratórios de pesquisa das universidades e outras instituições. Os SE, através dos softwares geradores ou shells existentes no mercado (principalmente os baseados em microcomputadores), estão ao alcance de uma grande parte das empresas. Como todas as inovações que surgiram na área de informática nas últimas décadas, também esta tecnologia deve ter a sua validade e utilidade comprovadas quando do seu uso corrente nas organizações.

Neste artigo, inicialmente, são descritos os $\mathrm{SE}$ e o potencial que eles representam para as empresas. Através da apresentação sucinta de alguns SE em gestão, já em operação nos EUA e na França, e da análise do seu uso, procurase ilustrar os benefícios obtidos e as limitações e dificuldades encontradas na implementação. A seguir são apresentados alguns dos SE em desenvolvimento para aplicações na área de gestão no Brasil. A partir da descrição e análise dos SE em operação, procurar-se-á destacar o desafio que existe para a efetiva implantação dos SE nas organizações brasileiras, em termos de benefícios possíveis e problemas potenciais ligados às peculiaridades do meio ambiente local.

\section{OS SISTEMAS ESPECIALISTAS}

Um Sistema Especialista - SE - pode ser caracterizado como um sistema que reproduz e explora os conhecimentos fornecidos por especialistas em áreas de conhecimento delimitadas ${ }^{1}$ Os especialistas têm a capacidade de resolver problemas difíceis, explicar os resultados obtidos, aprender, reestruturar o conhecimento e determinar as suas características relevantes. Eles também sabem o que não sabem. Os SE, por sua vez, com a tecnologia disponível atualmente, são bem mais limitados. Eles procuram mimetizar a resolução de problemas e são capazes de explicar alguns aspectos ligados à solução encontrada ${ }^{2}$. Esses

1. TRAHAND, Jacques \& HOPPEN, Norberto. "Sistemas especialistas e apoio à decisão em administração". Revista de Administração, 23(2):11-20, abril-junho, 1988 .

2.LEONARD-BARTON, Dorothy \& SVIOKLA, John. "Putting Expert Systems to Work". Harvard Business Review, março-abril, 1988, pp. 91-98. problemas normalmente são difíceis de ser representados, pois os especialistas são raros nas empresas e, muitas vezes, têm dificuldades em explicitar o seu modo de raciocínio de maneira sistemática. Conseqüentemente, um dos aspectos favoráveis da utilização de SE é a normatização de conhecimentos restritos e a sua difusão em toda a organização.

Por outro lado, não é fácil estruturar e programar os problemas com linguagens computacionais procedurais. Esses problemas contêm incerteza e outros aspectos qualitativos, o que é incompatível com as necessides das linguagens do tipo procedural, que requerem uma análise relativamente completa do problema. Por isto, os softwares, para a realização de SE, oferecem capacidades de programação declarativa e simbólica, através do uso de regras de produção, redes semânticas e objetos estruturados (frames) para a representação dos conhecimentos, tornando possível a reprodução de aspectos qualitativos do problema e permitindo o seu desenvolvimento segundo um processo evolutivo. Para tanto, a arquitetura dos SE fundamenta-se em:

- uma base de conhecimentos, que contém os fatos e regras que reunem o conhecimento do especialista;

- um interpretador de conhecimentos, também denominado motor ou mecanismo de inferência, que contém as estratégias de inferência e os controles que um especialista usa quando manipula fatos e regras;

- um módulo de explicação dos resultados obtidos pelo sistema;

- uma interface homem-máquina, com funcionalidades específicas para a interação usuário-SE e engenheiro do conhecimento-SE, quando da aquisição do conhecimento do especialista.

A figura 1 mostra a arquitetura de base de um Sistema Especialista.

Os SE podem ser desenvolvidos a partir de linguagens de programação não procedurais como Lisp e Prolog, ou a partir de shells ou geradores. Estes últimos são pacotes de software que configuram um SE vazio e integram ferramentas especializadas (editores, gerenciadores de comunicações etc.) para o desenvolvimento de aplicações. Dentre os softwares existentes, que usam o microcomputador como suporte, podem ser citados EXSYS, VPEXPERT, GURU, N-EXPERT e N-EXPERT $O B J E C T$. Dentre os que usam estações de trabalho específicas ou mainframes podem ser mencionados KEE, KES, ESE e KNOWLEDGE CRAFT. O uso de geradores para o desenvolvimento de SE nas empresas, em detrimento das linguagens, está ligado ao fato de que os geradores oferecem ferramentas de desenvolvimento e possibilidades de integração (via Banco de Dados) com outros Sistemas de Informação.

A abrangência do problema tratado com o auxílio de um SE é condicionada pela abrangência do conhecimento armazenado na base de conhecimentos. Quanto maior ela for, maior torna-se a base de conhecimentos $\mathrm{e}$ mais complexas a sua criação e atualização. Esse fato, juntamente com as performances computacionais ainda relativamente limi- 
Figura 1: Arquitetura de Base de um SE

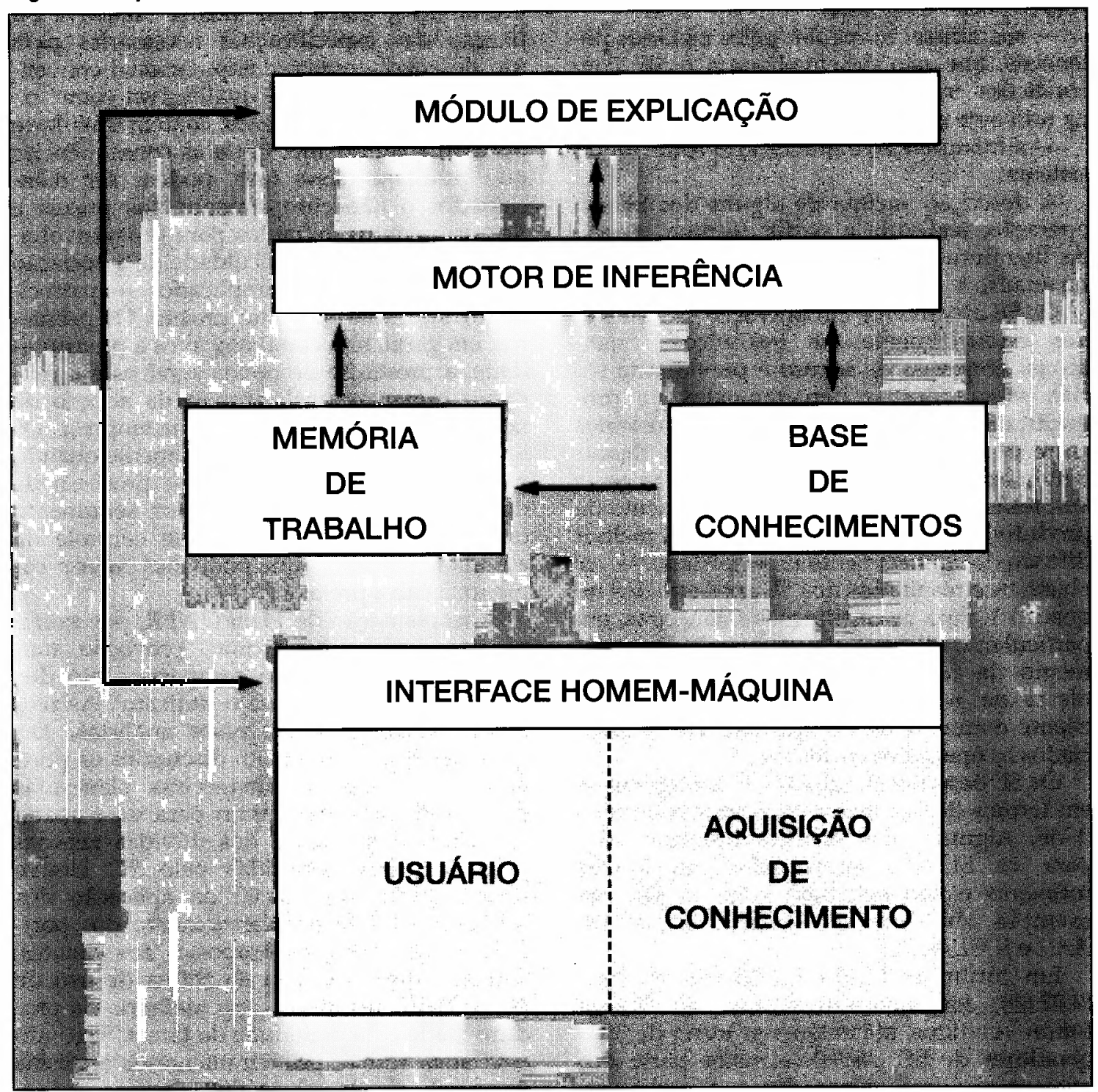

tadas e o problema da aquisição e validação do conhecimento constituem hoje os principais limites dos SE.

Os SE são empregados, essencialmente, em problemas de gestão do tipo interpretação, diagnóstico, previsão, planejamento, concepção e formação. As principais aplicações nessas áreas são:

- interpretação: de normas e regulamentos administrativos, jurídicos e fiscais, com o objetivo de prestar uma assistência;

- diagnóstico: análise financeira através de indicadores, análise e gestão de riscos de crédito, análise do risco que representam os fornecedores, manutenção de equipamentos (este último tipo de aplicação está situado entre a administração e a engenharia de produção);

- previsão: escolha de investimentos, gestão do plano de carreira do pessoal, levando em consideração mutações tecnológicas;

- planejamento e concepção: desenvolvimento de novas configurações de produtos, desenvolvimento de projetos;

- formação: suporte "inteligente" à instrução programada.

\section{ANÁLISE DE ALGUNS SISTEMAS ESPECIALISTAS OPERACIONAIS}

Esta análise utiliza, como base, SE de gestão implantados nos EUA e na França. Esses SE foram considerados operacionais segundo os critérios ${ }^{3}$ :

- inclusão da totalidade dos conhecimentos e fatos relativos ao problema na base de conhecimentos do sistema;
3. DUBREUIL, Sylvie H. \& NGOC, Jean-Michel T. "Vous avez dit 'opérationnel'"? Le Monde Informatique, 27.05.88, pp. 30-31. 
4. LEONARD-BARTON, DOrothy \& SVIOKLA, John. Op. cit.; RETOUR, Didier. "Conséquences de l'introduction de Systèmes Experts opérationnels en gestion d'entreprises: premières leçons francaises et étrangères". Actes du Congrès Système Expert et Gestion d'Entreprise, Versailles, setembro, 1988, pp. 100-110; CORITOU, Jean-Claude \& LESAFFRE, Francois-Marie. "SYMA: un système expert en milieu administratif". Actes des 8èmes Journées Internationales "Les Systèmes Experts et leurs Applications". Avignon, 1988 pp. 259-281; CASSEMAT, C et alii. "SAOR: un système intelligent pour la liquidation des retraites". Actes des 8èmes Journées Internationales "Les Systèmes Experts et leurs Applications". Avignon, 1988, pp. 283-302; LE MONDE INFORMATIQUE "Quand l'inspecteur degaine son portatif", 15.02 .88 pp. 53-54; LE MONDE INFOR MATIQUE. "JOSEPHINE opérationnel? Oui mais..." 30.05.88, p.56

5. LEONARD-BARTON, DOrothy \& SVIOKLA, John. Op. cit.

6. RETOUR, Didier. Op. cit.
- validação de sistema segundo um protocolo explícito e rigoroso;

- sua utilização regular pelos usuários potenciais, que não desenvolveram o SE, com condições ergonômicas e com uma inserção na rotina de trabalho adequadas;

- a manutenção e atualização rotineira do sistema.

A descrição sucinta de alguns dos SE em operação, realizada a partir de uma revisão da literatura especializada ${ }^{4}$ está apresentada no quadro 1.

Os SE atualmente em operação são utilizados essencialmente em instituições financeiras. Empresas de seguro e previdência social, seguradoras e departamentos de produção de indústrias também estão presentes entre os setores mais avançados no desenvolvimento e na utilização de SE. Para essas empresas, o objetivo essencial é o aumento da produtividade, obtido através de uma melhor difusão do conhecimento especializado - ver objetivos e resultados dos SE apresentados no quadro 1. Para as instituições financeiras, em particular, o objetivo consiste também no aumento da rentabilidade, obtido através da oferta de novos serviços ou produtos ao cliente e através da redução dos riscos associados às operações correntes.

Os SE descritos no quadro 1 distinguem-se em termos de sua maior ou menor complexidade. Algumas das maiores oportunidades para os SE são encontradas em tarefas rotineiras e não extensas ${ }^{5}$, como o são por exemplo Authorizer's Assistant, ExperTAX, $A A H$ e JOSEPHINE.

Em fórum realizado no Metrô de Paris (9.02.89), foi mencionado que na França foram vendidos, até então, em torno de 3000 geradores de SE (shells), a maior parte dos quais para microcomputadores. A partir desses geradores, foram desenvolvidos aproximadamente 1000 maquetes e protótipos e uma quantidade bem mais reduzida de $\mathrm{SE}$ operacionais (em torno de 300). Esses números, assim como as experiências descritas na literatura revisada, provocaram as reflexões apresentadas a seguir.

\section{Processo de desenvolvimento e uso dos SE}

\section{a) Desenvolvimento de Sistemas Especialistas}

$O$ processo de desenvolvimento de SE pode ser caracterizado como evolutivo. Várias maquetes são desenvolvidas pelos engenheiros do conhecimento (analistas) a partir da explicitação do conhecimento dos especialistas, até que um protótipo, que possa ser validado, seja concluído. Esta abordagem é adotada porque os problemas tratados com
SE normalmente são pouco estruturados, prestando-se mal a uma análise exaustiva e à fixação das especificações necessárias para um desenvolvimento computacional convencional. Esse processo é qualificável como experimental e, muitas vezes, contém uma forte dose de amadorismo. Entre as conseqüências que resultam desse fato, podem ser mencionados o não cumprimento dos prazos e dos orçamentos definidos para o desenvolvimento e, também, a dificuldade de associação dos principais atores implicados - patrocinadores e usuários - no projeto. Os primeiros, em geral, têm como objetivos a produtividade, a prestação de novos serviços e a mudança organizacional, através da adoção de novos elementos tecnológicos na empresa. Os usuários, por sua vez, principalmente quando não associados diretamente ao processo de desenvolvimento, podem ter um sentimento de perda de criatividade e de controle da atividade realizada, que pode lhes parecer como uma caixa preta.

A implantação de PlanPOWER, por exemplo, num primeiro tempo, provocou mudanças substanciais no comportamento dos analistas financeiros que o utilizam ${ }^{6}$. As reuniões realizadas entre esses analistas, nas quais habitualmente eram discutidos os portfólios de aplicações financeiras planejadas para os clientes, derivaram para uma apatia ou crítica dos erros e das dúvidas geradas pelas soluções fornecidas pelo SE. Houve uma redução substancial da aplicação dos analistas à tarefa de planejamento dos portfólios e nas soluções propostas aos clientes. Somente uma inversão da rotina de uso de PlanPOWER resultou numa melhoria da produtividade e da qualidade da tarefa. Segundo essa nova rotina, primeiramente os analistas desenvolvem um plano de aplicações financeiras de maneira convencional, o qual, em seguida, é confrontado com a solução proposta pelo $S E$ nas reuniões realizadas periodicamente. Nesse caso, PlanPOWER acabou sendo utilizado, essencialmente, como uma check-list inteligente e poderosa.

Ao processo de realização de SE podem ser associados ainda outros tipos de problemas.

$O$ primeiro diz respeito à definição das atividades para as quais são desenvolvidos os SE. Nesse caso, responder as perguntas abaixo permite uma melhor identificação das oportunidades:

"- será que existe na organização uma (ou mais) tarefa(s) que pode( $m$ ) ser melhorada(s) se os usuários tiverem mais tempo disponivel?

- será que essa tarefa pode ser melhorada, se o melhor especialista da organização a executar?

- será que essa tarefa pode ser melhorada, caso 


\section{Quadro 1: Sistemas Especialistas Operacionais}

\begin{tabular}{|c|c|c|c|c|c|}
\hline Sistema & Empresa & $\begin{array}{l}\text { Tipo de } \\
\text { Aplicação }\end{array}$ & $\begin{array}{c}\text { Tipo de } \\
\text { Problema }\end{array}$ & Objetivos & Resultados \\
\hline$X C O N$ & $\begin{array}{l}\text { Digital } \\
\text { (1973) } \\
\text { (EUA) }\end{array}$ & $\begin{array}{l}\text { configuração de } \\
\text { sistemas } \\
\text { computacionais }\end{array}$ & $\begin{array}{l}\text { planejamento } \\
\text { e concepção }\end{array}$ & $\begin{array}{l}\text { verificar componentes } \\
\text { de um sistema } \\
\text { computacional } \\
\text { evitar pré-montagem }\end{array}$ & $\begin{array}{l}\text { redução de custos operacionais } \\
\text { (US } \$ 25 \text { milhões) } \\
\text { aumento da qualidade dos } \\
\text { sistemas }\end{array}$ \\
\hline $\begin{array}{l}\text { Authorizer's } \\
\text { Assistant }\end{array}$ & $\begin{array}{l}\text { American } \\
\text { Express } \\
\text { (EUA) }\end{array}$ & $\begin{array}{l}\text { autorização } \\
\text { (análise) } \\
\text { de crédito }\end{array}$ & diagnóstico & $\begin{array}{l}\text { autorizar mais rapida- } \\
\text { e seguramente os } \\
\text { créditos } \\
\text { obter intormaçōes } \\
\text { adicionais mais rapidamente }\end{array}$ & $\begin{array}{l}\text { redução do tempo de resposta } \\
\text { aos comerciantes; } \\
\text { redução de perdas (riscos) } \\
\text { aumento da competitividade } \\
\text { de AMEX }\end{array}$ \\
\hline ExperTAX & $\begin{array}{l}\text { Cooper \& } \\
\text { Lybrand } \\
\text { (EUA) }\end{array}$ & $\begin{array}{l}\text { planejamento } \\
\text { de impostos } \\
\text { a pagar }\end{array}$ & $\begin{array}{l}\text { diagnóstico } \\
\text { e planejamento }\end{array}$ & $\begin{array}{l}\text { revisar impostos a } \\
\text { pagar de clientes de } \\
\text { escritórios de contabilidade } \\
\text { propor alternativas de } \\
\text { redução de impostos }\end{array}$ & $\begin{array}{l}\text { melhoria do uso dos } \\
\text { analistas júniors } \\
\text { processamento de um maior } \\
\text { número de casos }\end{array}$ \\
\hline Consultant & $\begin{array}{l}\text { IBM } \\
\text { (EUA) }\end{array}$ & $\begin{array}{l}\text { orçamento } \\
\text { serviços } \\
\text { de } \\
\text { reinstalação de } \\
\text { computadores }\end{array}$ & planejamento & $\begin{array}{l}\text { gerar orçamentos a } \\
\text { partir das especificidades } \\
\text { da instalação computacional } \\
\text { do cliente } \\
\text { permitir renegociação de } \\
\text { tarifas somente em casos } \\
\text { excepcionais }\end{array}$ & $\begin{array}{l}\text { melhoria dos conhecimentos } \\
\text { sobre o serviço e o orçamento } \\
\text { por parte dos técnicos } \\
\text { redução dos problemas } \\
\text { administrativos e das discussões } \\
\text { com os clientes }\end{array}$ \\
\hline$A A H$ & $\begin{array}{l}\text { Previdên- } \\
\text { cia Social } \\
(1987) \\
\text { (França) }\end{array}$ & auditoria & diagnóstico & $\begin{array}{l}\text { auditar concessão de } \\
\text { aposentadoria por } \\
\text { invalidez } \\
\text { reduzir erros e fraude }\end{array}$ & $\begin{array}{l}\text { - aumento da eficácia dos } \\
\text { inspetores } \\
\text { melhoria do serviço fornecido } \\
\text { melhoria da capacidade de } \\
\text { interpretaçäo dos regulamentos } \\
\text { pelos menos experientes }\end{array}$ \\
\hline PlanPOWER & $\begin{array}{l}\text { APEX } \\
\text { (EUA) }\end{array}$ & $\begin{array}{l}\text { gestão de } \\
\text { aplicações } \\
\text { financeiras }\end{array}$ & $\begin{array}{l}\text { diagnóstico e } \\
\text { planejamento }\end{array}$ & $\begin{array}{l}\text { aconselhar clientes na } \\
\text { gestâo de seus } \\
\text { pottólios de aplicaçōes }\end{array}$ & $\begin{array}{l}\text { aumento do númere de sugestōes } \\
\text { aumento da produtividade dos } \\
\text { consultores }\end{array}$ \\
\hline SAOR & $\begin{array}{l}\text { Instit.Gén. } \\
\text { Interprof. } \\
\text { Retraite } \\
\text { (França) }\end{array}$ & $\begin{array}{l}\text { processamento } \\
\text { solicitações de } \\
\text { aposentadoria } \\
\text { complementar }\end{array}$ & $\begin{array}{l}\text { interpretação } \\
\text { e planejamento }\end{array}$ & $\begin{array}{l}\text { orientar funcionários no } \\
\text { retraçamento das } \\
\text { carreiras e na interpretação } \\
\text { de regulamentos }\end{array}$ & $\begin{array}{l}\text { diminuição do tempo de } \\
\text { processamento } \\
\text { redução dos erros } \\
\text { melhoria da capacidade de } \\
\text { interpretação dos regulamentos } \\
\text { pelos menos experientes }\end{array}$ \\
\hline SYMA & $\begin{array}{l}\text { Serviço } \\
\text { de pensöes } \\
\text { das Forças } \\
\text { Armadas } \\
\text { (1987) } \\
\text { (França) }\end{array}$ & $\begin{array}{l}\text { processamento das } \\
\text { aposentadorias } \\
\text { dos } \\
\text { militares }\end{array}$ & $\begin{array}{l}\text { interpretação } \\
\text { e planejamento }\end{array}$ & $\begin{array}{l}\text { oferecer um suporte } \\
\text { inteligente aos funcionários, } \\
\text { tendo em vista o } \\
\text { grande tumover deste } \\
\text { serviço e as dificuldades } \\
\text { dos iniciantes }\end{array}$ & $\begin{array}{l}\text { aumento da produtividade } \\
\text { apoio aos funcionários menos } \\
\text { especializados } \\
\text { melhoria da capacidade de } \\
\text { interpretação dos regulamentos } \\
\text { pelos menos experientes }\end{array}$ \\
\hline JOSEPHINE & $\begin{array}{l}\text { Banco da } \\
\text { Bretanha } \\
\text { (1988) } \\
\text { (França) }\end{array}$ & $\begin{array}{l}\text { consultoria } \\
\text { em aplicações } \\
\text { financeiras }\end{array}$ & $\begin{array}{l}\text { diagnóstico } \\
\text { e planejamento }\end{array}$ & $\begin{array}{l}\text { oferecer um suporte } \\
\text { inteligente aos funcionários } \\
\text { das agências, } \\
\text { para aconselhar os } \\
\text { clientes em suas aplicações } \\
\text { financeiras }\end{array}$ & $\begin{array}{l}\text { guia inteligente da entrevista } \\
\text { e do contato com o cliente } \\
\text { atração tecnológica para } \\
\text { o cliente }\end{array}$ \\
\hline
\end{tabular}


existirem decisões mais consistentes (normalizadas) na organização?"7

Em termos da primeira questão, os sistemas Authorizer's Assistant e $S A O R$ permitem respostas mais rápidas e mais completas às solicitações. No caso da segunda pergunta, os sistemas XCON, AAH e PlanPOWER permitem a melhoria da qualidade da tarefa, através da difusão do conhecimento dos melhores especialistas. Finalmente, SAOR e $S Y M A$ tornam possível a obtenção de um processamento normalizado das aposentadorias, em locais e momentos diferentes.

\section{b) Difusão do conhecimento nas organizações}

$\mathrm{O}$ desenvolvimento de um SE é feito a partir do conhecimento fornecido por um ou vários especialistas e o sistema é utilizado por usuários menos ou não especializados. $\mathrm{O}$ papel dos primeiros continua essencial quando da implantação de SE nas organizações, porque eles devem participar continuamente da manutenção e da evolução do sistema. Os especialistas, ao consentirem a explicitação do conhecimento que contribui para o status que têm nas organizações, incorrem em certos riscos, como a perda de poder ou o questionamento da legitimidade do conhecimento. Considerando-se o papel essencial dos especialistas no desenvolvimento inicial e na evolução do SE, pode surgir a questão de como recompensá-los, para que participem ativamente de todo o processo.

Por outro lado, os usuários não especializados encontram um auxílio precioso para a tarefa que eles conhecem mal, podendo aprendê-la melhor. Mas as chefias intermediárias que, muitas vezes, são legitimadas pelo conhecimento especializado parcial que possuem, podem ter a sua função na empresa questionada quando se implementa um SE. O exemplo da transformação do uso de PlanPOWER e do risco que podem correr as chefias intermediárias de determinadas organizações dão uma idéia da importância do estudo e da tomada em consideração das relações usuário-SE-especialista, quando do desenvolvimento de um SE operacional.

7. LEONARD-BARTON, DOrothy \& SVIOKLA, John. Op. cit.

8. O'LEAREY, Daniel E. \& TURBAN Efraim. "The organizational impact of Expert Systems". Human Systems

Management, (7):11-19, 1987.

\section{Integração SE - Sistema de Informação da empresa}

Muitas vezes, para que um SE seja realmente útil para uma determinada tarefa, existe a necessidade de integração deste sistema com o Sistema de Informações da empresa, principalmente ao nível dos bancos de dados. Dentre os exemplos apresentados no quadro 1 , podem ser mencionados a inte- gração de XCON com o banco de dados componentes dos sistemas computacionais, de Authorizer's Assistant com os bancos de dados clientes (cadastros), de SAOR e SYMA com os bancos de dados que contêm informações pessoais e institucionais. Um dos problemas encontrados com o uso de JOSEPHINE foi a falta de integração deste SE com o banco de dados clientes do banco. Isso implicou na redigitação, ao se utilizar $\mathrm{o} S \mathrm{SE}$, de informações já disponíveis em outros bancos de dados, tais como quantidade e tipos de contas que o cliente possui na instituição e os respectivos saldos. Dessa maneira, o processo de consulta do SE e de aconselhamento do cliente tornou-se redundante e pouco interessante. Nesse caso, um dos critérios importantes para tornar um SE operacional - a sua inserção adequada na rotina de trabalho - não foi cumprido pelos analistas que realizaram o sistema.

A integração do SE com o Sistema de Informações da empresa torna o seu processo de desenvolvimento mais oneroso e delicado tecnicamente. $\mathrm{O}$ problema de compatibilidade entre o gerador normalmente utilizado para $o$ desenvolvimento do protótipo e a linguagem de gerenciamento do banco de dados ou outras aplicações computacionais mais clássicas - Sistemas de Apoio à Decisão ou modelos de simulação - deve ser levado em conta na análise dos custos e benefícios do $\mathrm{SE}$.

\section{Avaliação de $\mathrm{SE}$}

A avaliação de SE passa, inicialmente, por uma definição do que se procura avaliar: as capacidades técnicas, a rentabilidade econômica, as conseqüências humanas e as implicações organizacionais ${ }^{8}$. Tendo-se em vista as características e os propósitos dos $\mathrm{SE}$, essa tarefa não é das mais simples.

A partir dos objetivos definidos e dos resultados obtidos para os SE que figuram no quadro 1, é possível constatar que a avaliação desses sistemas tem basicamente conotações econômicas: ganho de produtividade e de rentabilidade. Em termos de uma análise clássica de custos e benefícios, estes últimos podem ser quantificados a partir dos ganhos de produtividade dos usuários, da redução dos riscos e do aumento da rentabilidade de produtos e serviços. Os custos, por sua vez, são estabelecidos a partir das aquisições de hard e de software, e a partir das diferentes etapas do ciclo de vida de um SE: aquisição de conhecimento, validação da base de conhecimento, adaptação do protótipo ao uso real, integração do protótipo em seu meio ambiente operacional, desenvolvimento da ergonomia e manutenção do sistema. A não inclusão de 
etapas como a integração no meio ambiente operacional ou a manutenção do sistema, que são corriqueiras em sistemas de informações convencionais, mas pouco mencionadas na literatura que trata do desenvolvimento de $\mathrm{SE}$, origina desvios orçamentários que podem, inclusive, inviabilizar a aplicação. A dificuldade de quantificar as etapas de caráter mais experimental, como a aquisição do conhecimento e a validação da base de conhecimento, é uma das origens dos desvios na avaliação dos custos.

As conseqüências humanas da implementação de SE, em parte já abordadas na análise do uso dos SE, provêm basicamente do temor sentido pelos usuários em relação à sua desqualificação, principalmente pelas chefias intermediárias, menos especializadas. Reações como obstaculizar, recusar, concorrer, cooperar ou aliar-se podem ser observadas. Uma definição mais clara dos objetivos e a associação, desde o início, de todos os implicados no projeto permite, ao menos em parte, reduzir as reações e facilitar uma apreciação global do sistema.

A avaliação das implicações organizacionais pode ser efetuada em relação à estrutura e funcionamento da empresa e à sua estratégia9. Para a primeira, a padronização de procedimentos realizados em locais e momentos diferentes, tais como a análise de crédito, a auditoria ou o planejamento de aplicações financeiras, é um dos elementos de avaliação, assim como a centralização ou a descentralização das atividades. Em termos de implicações estratégicas, o domínio da tecnologia de SE pode aumentar a competitividade da empresa, através do lançamento de novos produtos ou serviços, da melhoria dos serviços existentes e, também, de aumento da qualificação da força de trabalho, como nos casos de ExperTAX e SAOR. Estes permitiram aos analistas júniors adquirirem maior competência, habilitando-os para realizarem tarefas mais difíceis.

\section{SISTEMAS ESPECIALISTAS EM GESTÃO NO BRASIL}

Nesta seção, é apresentado um panorama geral, incompleto, do estado atual dos SE aplicados a problemas de gestão ${ }^{10}$.

\section{Oferta de Software e de Programas de Treinamento}

Uma rápida avaliação da oferta de software, especialmente de geradores ou shells que usam microcomputadores como suporte e que são os mais difundidos nos EUA e na França (70\% do total de geradores), mostra que ela é ainda bastante in- cipiente. Entre os produtos distribuídos, encontram-se EXSYS, PATER, FUZZY EX$P E R T$ e $L E V E L$ 5. Alguns dos produtos profissionais mais vendidos no mundo, tais como NEXPERT OBJECT e GURU ainda não estão disponíveis no Brasil. Em termos de shells, para equipamento de grande porte, estão sendo ofertados Expert Systems Environment e Knowledge Tool (IBM), KES, que também roda em microcomputadores, (UNISYS) e LEVEL 5 (SCI). A importância da disponibilidade de um grande número de geradores, com recursos diferentes, reside nas possibilidades de atender-se melhor uma ampla gama de aplicações da área de gestão. Um fenômeno semelhante já ocorreu com os softwares do tipo planilhas e gerenciadores de bancos de dados para microcomputadores.

A oferta de programas de treinamento de iniciação aos SE ou de formação para os geradores que existem no mercado também é reduzida. Os primeiros permitem difundir as potencialidades dos SE entre os responsáveis pela informática nas organizações. Nesse tipo de programas de treinamento oferecidos, podem ser mencionados os seminários desenvolvidos pela IBPI-Instituto Brasileiro de Pesquisa em Informática, SCI-Sistemas, Computação e Informática, pela SAD-Informática e Planejamento e pela própria IBM. O número de programas de formação para os produtos ofertados no mercado também é pequeno, um sinal de que a demanda ainda não se desenvolveu ou não está bem identificada.

A oferta reduzida de geradores e de seminários de iniciação é uma das causas da difusão restrita de informações sobre as potencialidades dos SE na resolução de problemas não convencionais nas organizações, tanto entre as diretorias e gerências de áreas funcionais, como entre os responsáveis pela informática.

\section{Desenvolvimento de Sistemas Especialistas}

O estágio de desenvolvimento de SE nas organizações ainda pode ser caracterizado como experimental.

Dentre as empresas que estão desenvolvendo internamente os seus $\mathrm{SE}$, a partir de geradores e linguagens de programação, rodando em microcomputadores e em equipamentos de grande porte, podem ser mencionados a IBM (controle de qualidade de discos rígidos na fábrica de Sumaré, SP), o Banco Itaú, o UNIBANCO, a Petrobrás (EXPERTEC, para manutenção de bombas hidráulicas $\mathrm{e}$ que está descrito com mais detalhes a seguir),
9. RETOUR, Didier. "L'évakuation des Systèmes Experts de gestion: propositions d'un cadre d'analyse". Papier de recherche $n^{0} 88$ 30 novembro 1988, 12p; MATTEI, Jacqueline. "Investissement informatique: une approche renouvelée de la rentabilité". Le Monde informatique, 07-09-87, pp. 77-79.

10. HOPPEN, Norberto \& TRAHAND, Jacques. "0 uso de Sistemas Especialistas em Administração no Brasil: um desafio para o início dos anos de 90". Anais do XXII Congresso Nacional de Informática, promovido pela SUCESU, São Paulo setembro de 1989, pp. 462-468. 
a Promon Engenharia (seleção de fundações para construção) e a Companhia do Metropolitano de São Paulo (com o sistema pioneiro SEDAFT de diagnóstico de falhas).

O SE EXPERTEC foi desenvolvido pela Petrobrás na Refinaria de Mataripe, Bahia. Ele diagnostica falhas em bombas hidráulicas centrífugas, baseado na análise de vibrações, permitindo a melhoria da manutenção preditiva. O sistema visa a reduzir a duração do diagnóstico que os mecânicos fazem em aproximadamente 700 bombas, restando-lhes, assim, mais tempo para a manutenção propriamente dita, contribuindo decisivamente para o aumento do número de inspeções.

O sistema, desenvolvido em ESE em equipamento de grande porte, atualmente com 86 regras, ainda tem o status de protótipo. Ele está sendo expandido para 120 regras, o que deverá permitir a sua integração com dados históricos sobre as bombas e sua manutenção. As respostas de $E X$ PERTEC, segundo o especialista, são confiáveis. Existem problemas de acesso ao sistema, ligados principalmente ao seu funcionamento em rede de teleprocessamento. Por outro lado, a fase de sensibilização da organização para a sua implantação definitiva, tanto na refinaria em que foi desenvolvido o protótipo, como nas outras refinarias, ainda está por ser feita.

A experiência descrita permite constatar, mais uma vez, que a inserção dos SE nas organizações é lenta; e que exige um longo processo de compreensão do seu potencial e de suas implicações no processo de trabalho.

Algumas empresas de consultoria também estão desenvolvendo SE. Entre elas, destacamse a Villares Informática, com os sistemas $D E$ BUG (diagnóstico de erros em programas Cobol), X-ELEV (configuração de projetos de elevadores), SICLO-M (cálculo de orçamentos para a manutenção de equipamentos pesados) e SEPA (programação do seqüenciamento de corridas de aço em aciaria). A Arthur Andersen, a

11. MAZZILLI, Cláudio \& HOPPEN, Norberto. "JHS: um protótipo de Sistema Especialista para análise de crédito de pessoa física". Anais do XXII Congresso Nacional de Informática, promovido pela SUCESU, São Paulo, setembro de 1989 , pp. 456-461.

12. KLEEBANK, Vivian. S/SEP: uma proposta de sistema baseado no conhecimento para escalonamento da produção. Dissertação de Mestrado, CPGCCUFRGS, março de 1989 $165 p$.

Os sistemas especialistas em gestão no brasil: um desafio
Os SE desenvolvidos ou em realização nessas empresas ainda se encontram, em sua grande maioria, no estágio de protótipo. Eles têm contribuído para a aquisição de competência na área.

\section{DESENVOLVIMENTO E USO DE SISTEMAS ESPECIALISTAS APLICADOS A PROBLENAS DE GESTÄO: UM DESAFIO}

Nesta seção, são apresentados o potencial que os SE representam para as empresas brasileiras, alguns dos problemas a serem resolvidos para aproveitar esse potencial e os ensinamentos que podem ser aproveitados da experiência adquirida por empresas estrangeiras que já têm sistemas em operação.

\section{Potencial Oferecido pelos SE}

Como já foi descrito na seção "Os Sistemas Especialistas", um dos resultados que pode ser obtido com o auxílio de um SE é a transferência de conhecimentos especializados. Esses conhecimentos, em geral, estão localizados nos níveis hierárquicos mais elevados das empresas. O número de especialistas é reduzido e eles representam um recurso escasso nas organizações. Considerando-se que uma grande parte da mão-de-obra disponível no Brasil tem qualificação insuficiente, a transferência do conhecimento especializado dos especialistas para os não especialistas, via $\mathrm{SE}$, permite desenvolver um melhor atendimento dos clientes, novos produtos (serviços) de difusão complexa em razão de sua tecnicidade, e obter maior produtividade.

Os SE também possibilitam a aceleração da formação e do aprendizado das pessoas menos qualificadas, através da transferência do conhecimento, utilizando-se o sistema como base. Nesse caso, o SE permite a sistematização do conhecimento existente na empresa e a sua posterior difusão via programas de treinamento específicos e perfeitamente adaptados à situação.

Uma das áreas para as quais a transferência de conhecimentos especializados oferece um grande potencial para as empresas brasileiras é a interpretação de normas e regulamentos jurídicos, fiscais, trabalhistas e administrativos, que sofrem freqüentes $\mathrm{mu}$ tações, difíceis de se manterem atualizadas na organização. Alguns dos SE apresentados no quadro $1-A A H, S A O R$ e $S Y M A-$ exemplificam o potencial desse tipo de aplicação. Também na área de manutenção existem boas possibilidades de desenvolvimento de SE, tanto na manutenção preditiva e corretiva de equipamentos complexos propria- 
mente dita, como em termos de treinamento.

\section{Problemas a Serem Resolvidos}

Para que o potencial dos SE seja efetivamente explorado no Brasil, cabe resolver alguns problemas, tais como o desenvolvimento de competência das empresas em aplicações, utilizando esse tipo de tecnologia e o aumento da disponibilidade de software gerador de SE no mercado.

Algumas das medidas que podem ser tomadas para se desenvolver a competência das empresas em SE são:

- participação em seminários de divulgação e de iniciação aos SE;

- formação técnica de analistas/engenheiros de conhecimento, através de programas de treinamento que abordam métodos de aquisição do conhecimento e que visam a tornar essa etapa do processo de aquisição do conhecimento mais eficiente;

- desenvolvimento de projetos-piloto nas empresas, talvez em conjunto com instituições de pesquisa com prática em aplicações em gestão, os quais devem ser analisados e difundidos na organização como um todo;

- inserção dos SE na estratégia da empresa, no Plano Diretor de Informática, com o objetivo mínimo de "manter um pé dentro" da tecnologia e do potencial das aplicações.

$O$ aumento da disponibilidade de software gerador de SE e a expansão da demanda por esse tipo de produto passam:

- por uma revisão da política da SEI, com o propósito de evitar a reinvenção local da roda em termos de geradores de SE de uso mais geral. A ampla variedade da oferta desse tipo de software no mercado internacional reproduz o fenômeno já ocorrido com outros softwares para microcomputadores, que procurou se adequar às diferentes necessidades dos usuários;

- pela distribuição de um maior número de geradores no mercado, associando-se as universidades $e$ os centros de formação $e$ pesquisa nessa difusão, pois essa tarefa implica no conhecimento das áreas de aplicação e dos limites dos SE, além do software propriamente dito;

- pela oferta de um maior número de seminários de iniciação e de aperfeiçoamento por parte das softwarehouses.

\section{Ensinamentos das Experiências Descritas}

Para que o desenvolvimento e uso dos SE possam se expandir no Brasil nos próximos anos, será dada ênfase, a seguir, a alguns ensinamentos extraídos das experiências realizadas:

1. Na identificação e seleção das aplicações: ter cuidado com as regras básicas descritas no item "Análise de Alguns Sistemas Especialistas Operacionais" e fixar-se, ao menos inicialmente, em problemas menos complexos e de solução mais simples.

2. Na escolha do software gerador de SE: atentar para critérios como características técnicas do gerador, ferramentas disponíveis para o desenvolvimento das aplicações, manutenção da evolução do gerador, treinamento disponível e documentação ${ }^{13}$. Os geradores não têm qualidade igual $\mathrm{e}$ as suas limitações podem trazer problemas no processo de aquisição de competência na área pelas empresas.

3. Na avaliação das aplicações de SE: incluir aspectos humanos e organizacionais, não se limitando aos problemas técnico-econômicos.

4. Na aquisição da competência em SE: analisar as vantagens da não centralização excessiva do processo de desenvolvimento de $\mathrm{SE}$. Este é fundado na competência dos especialistas de vários departamentos da organização e na dos analistas. Segundo a experiência de algumas grandes organizações, tais como a RATP (Metrô de Paris), a centralização da pilotagem do processo de desenvolvimento como um todo foi considerada a mais adequada. Essa abordagem permitiu, por um lado, o desenvolvimento de $\mathrm{SE}$ diversos por especialistas e engenheiros de conhecimento de vários setores funcionais da organização e, por outro lado, fez com que a empresa como um todo dominasse melhor o processo e adquirisse uma competência na área.

5. No processo de desenvolvimento: não subestimar as dificuldades da passagem de um protótipo para uma versão operacional do SE.

\section{CONCLUSÃO}

A título de conclusão, cabe salientar que o potencial oferecido pelos SE e pela técnica de programação não procedural associada a esses sistemas é muito grande para aplicações do tipo interpretação de normas, análise, diagnóstico etc. $O$ uso efetivo desse potencial depende muito da criatividade das empresas, em termos do desenvolvimento de aplicações de gestão hoje ainda não informatizadas. $O$ processo de introdução da tecnologia de $\mathrm{SE}$, pelas novidades que traz embutidas, é lento e possui características experimentais, pois ainda não existem metodologias de implementação consagradas. Conseqüentemente, os resultados devem ser avaliados num horizonte de médio e longo prazos ${ }^{14}$.]
13. LE MONDE INFORMATIQUE. “JOSEPHINE Opérationnel? Qui mais..." Op. cit.

14. A elaboração deste artigo contou com o apoio da CAPES, através do programa CAPES/COFECUB, $n^{\circ}$ $39 / 80$, e também do CNPq. 